Original Article

\title{
Effects of Active Individual Muscle Stretching on Muscle Function
}

\author{
Kouichi Nakamura, PT, MS ${ }^{1,2)^{*}}$, Takayuki Kodama, PT, PhD ${ }^{3)}$, Yoshito Mukaino, MD, PhD \\ 1) Department of Physical Therapy, Fukuoka Wajiro Rehabilitation College: 2-1-13 Wajirogaoka, \\ Higashiku, Fukuoka-city, Fukuoka 811-0213, Japan \\ 2) Faculty of Sports and Health Science, Fukuoka University, Japan \\ 3) Department of Physical Therapy, Faculty of Health Science, Kyoto Tachibana University, Japan
}

\begin{abstract}
Purpose] We investigated the effect of active individual muscle stretching (AID) on muscle function. [Subjects] We used the right legs of 40 healthy male students. [Methods] Subjects were divided into an AID group, which performed stretching, and a control group, which did not. We examined and compared muscle function before and after stretching in the AID and control groups using a goniometer and Cybex equipment. [Results] A significant increase in flexibility and a significant decrease in muscle strength output were observed in the AID group after the intervention. [Conclusion] These results suggest that AID induces an increase in flexibility and a temporary decrease in muscle output strength.

Key words: Active individual muscle stretching, Muscle function, Flexibility
\end{abstract}

(This article was submitted Aug. 9, 2013, and was accepted Sep. 22, 2013)

\section{INTRODUCTION}

Stretching was introduced in a sports coaching program on TV at the beginning of the 1980s in Japan, which led to the publication of many stretching-associated books for the general public and a so-called stretching boom ${ }^{1)}$. Based on previous studies, the common aims of stretching are to improve joint range of motion (flexibility), decrease muscle tension ${ }^{2-9)}$, improve circulation ${ }^{2,10,11)}$, relieve muscle pain $^{2,12,13)}$, prevent injury, and improve athletic performance ${ }^{1,2,13)}$. Stretching using the responses of the nervous system such as proprioceptive neuromuscular facilitation is currently attracting attention in the field of sports. Stretching is also performed in combination with yoga or Pilates, which attaches importance to postures and breathing techniques. Thus, various types and purposes of stretching have been reported. However, a number of theories on the association between stretching methods and their effects exist, and this issue is still controversial.

Individual muscle stretching (ID stretching) developed by Suzuki et al. ${ }^{2}$ aims to increase muscle flexibility and extensibility, and improve joint range of motion and dexterity associated with muscles. ID stretching has been widely used in hospitals, clinics, and the field of sports, mainly by physical therapists, since 1999. ID stretching is characterized $^{2)}$ by passive static stretching of individual

\footnotetext{
*Corresponding author. Kouichi Nakamura (E-mail: nakamura@fukuokawajiro-reha.jp)

C2014 The Society of Physical Therapy Science. Published by IPEC Inc. This is an open-access article distributed under the terms of the Creative Commons Attribution Non-Commercial No Derivatives (by-ncnd) License $<$ http://creativecommons.org/licenses/by-nc-nd/3.0/> .
}

muscles using Ib inhibition, detailed anatomical and physiological knowledge, such as that of muscle arrangements and responses to stimuli, and combination with isometric contraction, depending on the degree of muscle tension required. Our previous study ${ }^{14)}$ of ID stretching showed improvements in flexibility, a decrease in muscle strength output, and psychologically positive changes, which were better than those of conventional passive static stretching. However, in the conditioning field, it is important that not only physical therapists and trainers perform ID stretching, but also that patients and athletes control and perform this stretching by themselves.

Even if the extensibility and flexibility of soft tissues representative of the muscles improve, they readily decrease due to posture, exercise, or stress ${ }^{15)}$. Therefore, muscles treated by ID stretching to reduce muscle tension or pain, should be continuously stretched by patients or athletes to maintain soft tissue function ${ }^{15)}$. Unlike passive ID stretching, which is performed by therapists, active ID stretching (AID) was developed in 2007 ${ }^{15}$ ) and is performed by patients and athletes by themselves. AID has since been performed as a bedside or home exercise by patients or athletes under the management of a physical therapist. However, to the best of our knowledge, no studies have evaluated the effects of AID on muscle function. Therefore, this study was performed to evaluate the effects of AID on muscle function, using a goniometer (Medica) to determine range of motion, and an isokinetic dynamometer (Cybex770NORM, Medica). 


\section{SUBJECTS AND METHODS}

\section{Subjects}

The subjects were 40 healthy male students (40 right lower limbs) with no previous history of disease in their lower limbs. Their mean age was $20.8 \pm 1.6$ years, their mean height was $171.8 \pm 5.4 \mathrm{~cm}$, and their mean body weight was $66.4 \pm 7.3 \mathrm{~kg}$.

This study was approved by the Research Ethical Committee of Fukuoka Hoken Gakuin, and oral and written explanations about the contents and risks of this study were given to all subjects prior to the study. All subjects signed the consent form after understanding the study contents, and participated in this study.

\section{Methods}

Subjects were randomly and evenly allocated to 2 groups (20 subjects each) which performed (AID group) or did not perform AID (control group).

The soleus was evaluated as an ankle plantar flexor muscle. Range of motion testing (ROM-T) and measurement of isokinetic plantar flexor muscle strength were performed before and after stretching. To evaluate flexibility, ROM-T was performed according to the methods established by the Measurement Standards Committee of the Japanese Association of Rehabilitation Medicine ${ }^{16}$. The ankle dorsiflexion range of motion was measured using a goniometer, perpendicularly from the knee-flexed position to the fibula as the primary axis, and the 5th metatarsal bone as the movement axis. Two physical therapists (clinical experience, 12.5 \pm 2.6 years) other than the authors were performed these measurements. One performed fixation, and the other performed the measurement, and after exchanging roles, the measurement was taken again. An isokinetic dynamometer (Cybex770-NORM) was used to measure isokinetic muscle strength output. Based on the study of Yoshino et al. ${ }^{17)}$, evaluations were performed at low $(60 \mathrm{deg} / \mathrm{sec})$, intermediate $(180 \mathrm{deg} / \mathrm{sec})$, and high $(300 \mathrm{deg} / \mathrm{sec})$ angular velocities A ankle dorsiflexion with maximum effort was performed 3 consecutive times, and the mean peak torque achieved at each angular velocity was calculated ${ }^{14)}$.

Measurements at one angular velocity were taken on 1 day. To avoid order effects, measurements at the 3 angular velocities were randomly taken on different days.

To stretch the soleus in the AID group, the right forefoot was bilaterally held with both hands, and the right ankle was dorsiflexed while the center of gravity was posteriorly moved (Fig. 1). External force applied to the test limb during stretching was controlled at $5 \mathrm{kgf}$ using a hand-held dynamometer (FET-102, Medix Japan) which was used for the quantitative evaluation of muscle strength ${ }^{14,18)}$. The stretching instructors were 2 physical therapists (clinical experience, $10.5 \pm 2.4$ years) other than the authors and the physical therapists who performed ROM-T. One of the two physical therapists gave instructions, and the other took the measurement. The control group did not perform stretching, and measurements were taken after a resting time similar to the stretching time of the AID group.

To induce exercise conditions before the evaluation,

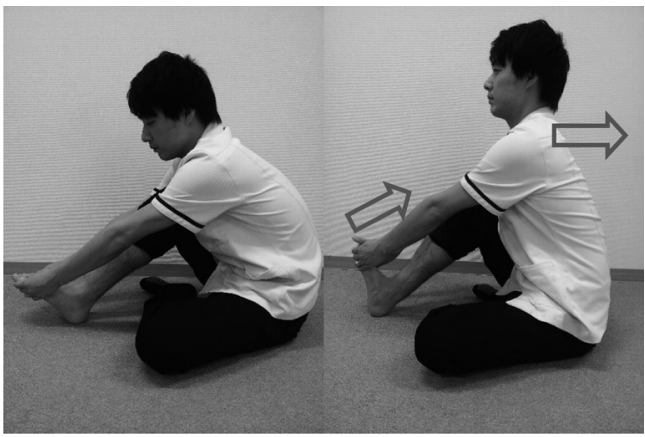

Fig.1. Active individual muscle stretching of the soleus

Table 1. Range of motion before and after the intervention

\begin{tabular}{lcl}
\hline Group & Before & After \\
\hline AID & $19.5 \pm 3.6$ & $25.2 \pm 3.0^{*}$ \\
Control & $19.7 \pm 3.5$ & $20.1 \pm 3.2$ \\
\hline
\end{tabular}

AID: Active Individual Muscle Stretching

Before: Before stretching After: After stretching

$\mathrm{n}=40$, the values shown are angles $\left(^{\circ}\right)$

Mean \pm standard deviation $* \mathrm{p}<0.05$

all subjects performed an ergometer exercise (5 min, $60 \mathrm{~W})^{19,20)}$

Statistical analysis was performed as follows. Flexibility was analyzed using two-way repeated measures analysis of variance with the group $(2$ levels: AID $\times$ control $)$ and the measurement value of the foot dorsiflexion range of motion ( 2 levels: before $\times$ after stretching) as the two factors. Muscle strength output was analyzed using a 3-way analysis of variance with the group $(2$ levels: AID $\times$ control), peak torque values of the two groups (2 levels: before $\times$ after stretching), and the angular velocity (3 levels: $60 \times$ $180 \times 300 \mathrm{deg} / \mathrm{sec}$ ) as the 3 factors. Fisher's PLSD was used for multiple comparison tests. $p<0.05$ was regarded as significant in all analyses. SPSS 12.0.J for Windows was used as the statistical software.

\section{RESULTS}

Both the group and ROM value had main effects on flexibility. A comparison between the two groups showed significant improvements in flexibility in the AID group (Table $1)$.

A comparison of the ankle dorsiflexion range between before and after the intervention in each group showed a significant improvement in flexibility in the AID group $(\mathrm{p}<$ $0.05)$, but and no significant difference in the control group $(\mathrm{p}>0.05)($ Table 1$)$.

Muscle strength output was significantly lower after stretching in the AID group than in the control group. A comparison of muscle strength output between before and after the intervention in each group revealed a significant decrease after the intervention in the AID group only ( $p<$ 
Table 2. Isokinetic muscle strength output before and after the intervention

\begin{tabular}{lcccccc}
\hline & \multicolumn{2}{c}{$60 \mathrm{deg} / \mathrm{sec}$} & \multicolumn{2}{c}{$180 \mathrm{deg} / \mathrm{sec}$} & \multicolumn{2}{c}{$300 \mathrm{deg} / \mathrm{sec}$} \\
\hline Group & Before & After & Before & After & Before & After \\
\hline AID & $75.4 \pm 28.6$ & $53.7 \pm 22.3^{*}$ & $55.2 \pm 15.3$ & $45.2 \pm 14.7$ & $44.4 \pm 14.1$ & $40.5 \pm 12.6$ \\
Control & $74.1 \pm 27.4$ & $72.7 \pm 23.4$ & $53.1 \pm 13.6$ & $52.5 \pm 11.6$ & $45.4 \pm 10.2$ & $44.3 \pm 9.6$ \\
\hline
\end{tabular}

AID: Active Individual Muscle Stretching

Before: Before stretching After: After stretching

$\mathrm{n}=40$, the values are shown as peak torques $(\mathrm{Nm})$.

Mean \pm SD, $* \mathrm{p}<0.05$

0.05) (Table 2). Muscle strength output here means muscle strength of plantarflexion.

A comparison of the peak torque between before and after the intervention at each angular velocity showed a significant difference only at an angular velocity of $60 \mathrm{deg} / \mathrm{sec}$ in the AID group $(\mathrm{p}<0.05)$. No significant differences were observed between before and after the intervention in the control group $(\mathrm{p}<0.05)$ (Table 2$)$.

\section{DISCUSSION}

This study evaluated the effects of AID on muscle function in terms of flexibility and isokinetic muscle strength output.

A significant improvement in flexibility after stretching was observed in the AID group, but not in the control group. This finding together with those of previous studies indicates the responses of the nervous system to stretching. Helda et al. ${ }^{21)}$ reported that a prolonged stretch of muscle spindles inhibited their afferent activity, which resulted in a decrease in muscle tension. Fowles et al. ${ }^{22)}$ reported that prolonged static stretching induced responses in Golgi tendon organs and nociceptors, which inhibited muscle tension. These responses of the nervous system can also be explained by a delay and decrease in the integral value ${ }^{21,23)}$ of the stretch reflex, and a decrease in muscle tension may also have resulted in improvements in flexibility. We speculate that these responses by the nervous system occurred in the body since, AID can also be classified as static stretching, and results similar to those in previous studies were obtained. The reason why a few improvement trends were seen in the control group was same position has range of motion measurement and AID and thinks that a temporary stretching effect was given.

Muscle strength output after the intervention was lower in the AID group than in the control group. This result together with those of previous studies suggests the involvement of the physical properties of muscle tissue. Morse et al. ${ }^{7)}$ reported a decrease in the elasticity of muscle connective tissue (increased extensibility) as acute changes immediately after stretching. Cramer et al. ${ }^{25)}$ demonstrated that the sarcomeres of muscle fibers were stretched by stretching and Teramoto et al. ${ }^{26)}$ reported that tendons were also stretched. These studies suggest that muscle fibers are longer after stretching than before, due to the physical characteristics of the muscle. Based on the muscle tension-length relationship, a certain muscle length is necessary to exert maximum contraction tension ${ }^{27)}$. Since muscle length was reported to be longer after stretching than before, even at the same joint angle, due to sarcomere/tendon elongation, muscle strength may decrease after stretching ${ }^{28)}$. This increase in muscle length may have caused decrease in muscle strength output which was observed as an acute change immediately after stretching in the present as well as previous studies.

An evaluation of isokinetic muscle strength output exerted at each angular velocity revealed a decrease after the intervention only at an angular velocity of $60 \mathrm{deg} / \mathrm{sec}$ in the AID group. Nelson et al. ${ }^{29)}$ reported that the effects of stretching were marked at $60 \mathrm{deg} / \mathrm{sec}$ because this low angular velocity resembles the velocity of isometric exercise, and muscle contraction occurs at a lower velocity. AID as well as ID stretching, in which an individual muscle is selected for stretching, was more susceptible to Ib inhibition, which had inhibitory effects on muscle tension. Muscle tension may have been associated with the decrease in muscle strength output at the low angular velocity in the AID group.

The results of this study suggest that AID as self stretching, as well as passive static stretching ${ }^{2-9}$ ), improves flexibility and decreases muscle strength output, showing potential in the self-conditioning field. In this study, the expression "a decrease in muscle strength output" was used; however, changes in muscle tension and the inhibitory effects of muscle tension, which may be present in the background, were not evaluated. Neurophysiological studies using electromyography ${ }^{30,31)}$ should be performed in the future to more thoroughly evaluate the inhibitory effects of muscle tension. In addition, an evaluation that assesses performance using basic and sport actions ${ }^{24)}$ is required, because many muscles are involved in actual joint exercise. An evaluation of the duration of effects ${ }^{28)}$ of home exercise utilizing AID is also needed.

\section{REFERENCES}

1) Inoue S, Koyanagi M, Nakae T, et al.: Athlete Care Manua. Tokyo: Bunkodo, 2007, pp 2-14.

2) Suzuki S, Hirano Y, Suzuki T: ID stretching, 2nd ed. Tokyo: Miwa-Shoten Ltd., 2006, pp 2-46.

3) Avela J, Kyrolainen H, Komi PV: Altered reflex sensitivity after repeated and prolonged passive muscle stretching. J Appl Physiol, 1999, 86: 12831291. [Medline]

4) Kokkonen J, Nelson AG, Cornwel A: Acute muscle stretching inhibits maximal strength performance. Res Q Exerc Sport, 1998, 69: 411-415. [Medline] [CrossRef]

5) Guissard N, Duchateau J: Effect of static stretch training on neuro and mechanical properties of the human planter-flexor muscles. Muscle Nerve, 2004, 29: 248-255. [Medline] [CrossRef] 
6) Cramer JT, Housh TJ, Weir JP, et al.: The acute effects of static stretching on peak torque, mean power output, electromyography, and mechanomyography. Eur J Appl Physiol, 2005, 93: 530-539. [Medline] [CrossRef]

7) Morse CI, Degens H, Seynnes OR, et al.: The acute effect of stretching on the passive stiffness of the human gastrocnemius muscle tendon unit. J Physiol, 2008, 586: 97-106. [Medline] [CrossRef]

8) Yamaguchi T, Ishii K, Yamanaka M, et al.: Effect of static stretching for 30 seconds and dynamic stretching on leg extension power. J Strength Cond Res, 2006, 19: 677-683.

9) Behm DG, Bambury A, Cahill F, et al.: Effect of acute static stretching on force, balance, reaction time, and movement time. Med Sci Sports Exerc, 2004, 36: 1397-1402. [Medline] [CrossRef]

10) Suzuki S: Testing of the effects of physical therapy on myofascial pain by imaging. J Jpn Phys Ther Assoc, 2005, 32: 32-33.

11) Kageyama $S$ : Effects of stretching and jogging in warming up (cool down) using color thermography. Descente Sports Sci, 1996, 3: 306-308.

12) Moritani T: Electrophysiological clarification of the physiological effects of stretching on muscle pain. Descente Sports Sci, 1987, 8: 212-219.

13) Yamashita $T$, Sekine M, Takebayashi $T$, et al.: Physiologic mechanisms of the muscle stretching exercise: effects of muscle stretching on the neuromuscular transmission. J Phys Med, 2001, 12: 20-26.

14) Nakamura K, Mukaino Y, Kodama T: Effects of individual muscle stretching on mind and body. Rigakuryoho Kagaku, 2011, 26: 13-17 (in Japanese). [CrossRef]

15) Suzuki S, Hirano Y, Suzuki T: Active ID stretching. Tokyo: Miwa-Shoten Ltd., 2007, pp 2-8.

16) Nara I, Uchiyama H, Ogawa K, et al.: Physical therapy examination · measurement guide, 2nd ed. Tokyo: Bunkodo, 2009: pp 179-180.

17) Yoshino N, Miwa M, Suzuki K, et al.: Verification of angular verlocity by Cybex 770-NORM. Yamagata J Health Sci, 2002, 5: 51-56.

18) Inami $T$, Shimizu $T$, Miyagawa $H$, et al.: Influence of bi-articular muscle stretching on isokinetic muscle force. Jpn J Clin Sports Med, 2008, 16 395-401.

19) Marsh D, Sleivert G: Effect of precooling on high intensity cycling performance. Br J Sports Med, 1999, 33: 393-397. [Medline] [CrossRef]
20) Hoffrén M, Isikawa M, Komi PV: Age-related neuromuscular function during drop jumps. J Appl Physiol, 2007, 103: 1276-1283. [Medline] [CrossRef]

21) Herda TJ, Ryan ED, Smith AE, et al.: Acute effects of passive stretching vs. vibration on the neuromuscular function of the planter flexors. Scand J Med Sci Sports, 2009, 19: 703-713. [CrossRef]

22) Fowles JR, Sale DG, MacDougall JD, et al.: Reduced strength after passive stretch of the human plantar flexors. J Appl Physiol, 2000, 89: 1179-1188. [Medline]

23) Weir DE, Tingley J, Elder DC, et al.: Acute passive stretching alters the mechanical properties of human plantar flexors and the optical angle for maximal voluntary contraction. J Appl Physiol, 2005, 93: 614-623.

24) Hamada K, Sasaki M: Effects of static stretching on jumping ability: from physiological and functional aspects. Rigakuryoho Kagaku, 2008, 23: 463-467. [CrossRef]

25) Cramer JT, Beck TW, Housh TJ, et al.: Acute effects of static stretching on characteristics of the Isokinetic angle-torque relationship, surface electromyography. J Sports Sci, 2007, 25: 687-698. [Medline] [CrossRef]

26) Teramoto A, Luo ZP: Temporary tendon stretching by preconditioning. Clin Biomech (Bristol, Avon), 2008, 23: 619-622. [Medline] [CrossRef]

27) Hongo T, Hiroshige T, Toyota J, et al.: Standard physiology, 6th ed. Tokyo: Igaku-Shoin, 2005, pp 107-127.

28) Kimoto Y, Endo S: Time course effects of static stretching on measures of strength and range of motion of the hamstring muscle. Health Sci Bull Akita Univ, 2011, 19: 27-33.

29) Nelson AG, Allen JD, Cornwell A, et al.: Inhibition of maximal voluntary isokinetic torque production following stretching. J Strength Cond Res, 2001, 15: 241-246. [Medline]

30) Costa PB, Ryan ED, Herda TJ, et al.: Effects of static stretching on the hamstrings to quadriceps ratio and electromyographic amplitude in men. J Sports Med Phys Fitness, 2009, 49: 401-409. [Medline]

31) Marques AP, Vasconcelos AP, Cabral CM, et al.: Effect of frequency of static stretching on flexibility, hamstring tightness and electromyographic activity. Braz J Med Biol Res, 2009, 42: 949-953. [Medline] [CrossRef] 